\title{
COMUNICAÇÃO
}

\section{FRACO DESEMPENHO DO ALBENDAZOL NO TRATAMENTO DA ESTRONGILOIDÍASE}

\author{
Ronaldo Cesar Borges Gryschek, Vicente Amato Neto, \\ Luís Matsubara e Rubens Campos
}

A comercialização do albendazol no Brasil, infelizmente, apontou a favor desse fármaco qualidade exageradas, frisando espectro de ação não verídico, a respeito de helmintíases intestinais. $\mathrm{Na}$ verdade, porém, se valorizados os irrefutáveis conhecimentos científicos, esse medicamento passou a representar o mais ativo frente à ancilostomíase, debelando satisfatoriamente a ascaridíase e a enterobíase, sem constituir progresso sensivel quanto ao tratamento da tricocefaliase. No que tange à estrongiloidíase e à himenolepíase causada por Hymenolepis nana, deve ficar bem ressaltado, o remédio citado não constitui avanço, uma vez que outros recursos afiguram-se melhores ${ }^{13456}$.

Como acumulamos observações suplementares relacionadas à infecção pelo Strongyloides stercoralis, julgamos importante divulgá-las.

Compuseram a casuística 45 indivíduos infectados pelo $S$. stercoralis, conforme resultados de exames parasitológicos de fezes pouco antes realizados. Dezesseis eram do sexo feminino, as idades oscilaram entre 16 a 76 anos e, clinicamente, só houve menção, por um terço das pessoas consideradas, a distúrbios discretos, exemplificados por diarréia, dor abdominal, náusea ou vômito. Vinte e dois receberam o albendazol ("Zentel Smith Kline \& Cia."); a eles foram administrados dois comprimidos com $200 \mathrm{mg}$ cada, cotidianamente, durante três dias. A vinte e três demos, para comparação e também para avaliar o valor de preparação desse tipo, associação de mebendazol com tiabendazol ("Helmiben - Biolab Indústrias Farmacêuticas S.A."); dois comprimidos com $100 \mathrm{mg}$ e $166 \mathrm{mg}$, respectivamente, dos compostos citados, corresponderam às doses atribuídas duas vezes em 24 horas, no decurso de três dias.

Os controles pós-tratamentos dependeram de análises de matérias fecais oito, nove e dez dias após o término dos tratamentos, mediante uso da técnica de Baermann ${ }^{2}$. Admitimos que teve lugar cura quando todas essas avaliações não mostraram larvas do helminto.

Como resultados apuramos que o albendazol propiciou oito sucessos $(30,36 \%)$ e o produto com mebendazol-tiabendazol $14(60,86 \%)$.

A tolerância pôde ser interpretada como muito boa e em apenas cinco eventos surgiram diarréia ou náusea, de pequenas intensidades e talvez imputáveis às preparações tomadas.

Diante do exposto, deduzimos que o remédio misto possui eficácia de porte mediano, suplantada pelo emprego habitual de tiabendazol isoladamente ou, mormente, do cambendazol. Com o albendazol, no entanto, demarcamos elevada porcentagem de fracassos, deixando evidente que não se justifica preferi-lo quando pretendida a cura da estrongiloidíase, Várias razões apoiamessa assertiva, entre as quais destacamos a citada baixa capacidade no sentido de debelar a infecção motivada pelo $S$. stercoralis e a disponibilidade de fármacos mais eficientes. Fica evidente, então, que é criticável a postura da empresa propugnadora dessa indicação, no Brasil, gerando equívoco de ordem assistencial e desmerecendo corretos respaldos científicos, opostos a opiniões não sustentadas por investigações confiáveis.

\footnotetext{
Laboratório de Investigação Médica-Parasitologia, do Hospital das Clínicas, da Faculdade de Medicina da Universidade de São Paulo.

Endereço para correspondência: Dr. Ronaldo Cesar Borges Gryschek, Laboratório de Investigação Médica-Parasitológica/ HC/FM/USP. Av. Dr. Arnaldo 455, 01246-000 São Paulo, SP, Brasil.

Recebido para publicação em 06/03/92.
} 
Comunicação. Gryschek RCB, Amato Neto V, Matsubara L, Campos R. Fraco desempenho do albendazol no tratamento da estrongiloidiase. Revista da Sociedade Brasileira de Medicina Tropical 25:205-206, jul-set, 1992.

\section{REFERÊNCIAS BIBLIOGRÁFICAS}

1. Amato Neto V, Castilho VLP, Moreira AAB, Sant'Ana EJ, Pinto PLS, Campos R, Padilha LAA. Eficácia do albendazol no tratamento da enterobíase. Revista do Instituto de Medicina Tropical de São Paulo 27:143-144, 1985.

2. Amato Neto V, Corrêa LL. Exame parasitológico de fezes. $5^{a}$ edição, Sarvier, São Paulo, 1990.

3. Amato Neto V, Moreira AAB, Campos R, Lazzaro ESM, Chiaramelli MCG, Castilho VLR, Gomes AEC, Pinto PLS. Tratamento da ancilostomíase por meio do albendazol. Revista do Instituto de Medicina Tropical de São Paulo 25:42-46, 1983.

4. Amato Neto V, Moreira AAB, Campos R, Lazzaro ESM, Chiaramelli MCG, Pinto PLS, Silva GR, Nishioka SA, Leite RM. Tratamento da ancilostomíase, ascaridíase e tricocefalíase por meio do albendazolou do mebendazol. Revista do Instituto de Medicina Tropical de São Paulo 25:294-299, 1983.

5. Amato Neto V, Pinto PLS, Moreira AAB, Campos R, Sant'Ana EJ, Levai EV, Padilha LAA, Takiguti CK. Avaliação da atividade terapêutica do albendazol em ratos experimentalmente infectados com Strongyloides venezuelensis. Revista do Instituto de Medicina Tropical de São Paulo 28:181-184, 1986.

6. Campos R, Moreira AAB, Castilho VLP, Amato Neto V, Guizelini E, Pinto PLS. Tratamento da ascaridíase e da tricocefalíase por meio do albendazol. Arquivos Brasileiros de Medicina 57:185-186, 1983. 